\title{
OS PERCALÇOS DE UMA POLÍTICA: RELAÇÃO À BRASILEIRA ENTRE O ESTADO E A POLÍTICA DE COMBATE AO CÂNCER
}

\author{
THE DRAWBACKS OF A POLICY: RELATIONSHIP TO BRAZILIAN BETWEEN THE STATE \\ AND THE POLICY TO FIGHT CANCER
}

Lourdes Karoline Almeida Silva ${ }^{1}$

Francisco Oliveira Barros Júnior (orientador) ${ }^{2}$

\begin{abstract}
RESUMO
Este artigo trabalha a relação sociopolítica e histórica entre o Estado brasileiro e a construção da política nacional de combate e controle do câncer, enfatizando, especialmente, a tessitura brasileira das duas últimas décadas (1990-2000), em que houve o desmonte da seguridade social, da qual a saúde é um dos três pilares junto com a previdência e assistência social. Para tanto, fez-se uma análise da construção e crise do Estado de Bem-Estar Social e implantação retardatária dos ajustes estruturais neoliberais, no Brasil. Destaca-se nesse percurso, a Política Nacional de Atenção Oncológica (PNAO), instituída em 2005, e dirigida pelo Instituto Nacional de Câncer. Conclui-se que as iniciativas do governo federal em construir mecanismos legais, como a PNAO, vinculados à proposta inicial do Sistema Único de Saúde não estão sendo acompanhadas de condições concretas para a sua efetivação. Pois quanto ao câncer, as bases legais através da iniciativa política pública estatal para seu controle e combate foram postas, mas essa política não recebe o devido financiamento para sua realização. Aliás, essa política é acompanhada intimamente pelo processo de publicização, em que o apelo ao voluntariado ou à solidariedade da sociedade faz-se empírica e ideologicamente presente.
\end{abstract}

PALAVRAS-CHAVE: Estado. Saúde. Seguridade Social. Cancer.

\begin{abstract}
This article shows the socio political and historical relation between the Brazilian state and the construction of national policy to fight and control cancer that especially emphasizes the Brazilian organization in the last two decades (1990-2000) when there was a disassembly of the social security, which health is one of the three pillars joined with social security and welfare. This way, an analysis was done in the construction and crisis of the Welfare State and a deferred insertion of the neoliberal structural adjustment in Brazil. It displays the National Oncological Care (PNAO), established in 2005, and directed by the National Cancer Institute. It is concluded that the federal government initiatives in building legal mechanisms like PNAO linked to the initial proposal of the Health System are not accompanied by the concrete conditions for its realization. In relation to cancer, the legal bases through the public policy initiative by government to control and fight were put, but this policy does not receive the rightful funding for its realization. As a matter of fact, this policy is followed closely by the process of

\footnotetext{
${ }^{1}$ Bacharel em Ciências Sociais (UFPI), Mestre e doutoranda em Políticas Públicas (UFPI). Professora Assistente nível I de Sociologia da Universidade Estadual do Piauí, Campus Alexandre Alves de Oliveira. Telefone 86 9917-5117, e-mail: lourdeskaroline.sociologa@bol.com.br.

2 Professor doutor, de Sociologia da Universidade Federal do Piauí.

Serv. Soc. \& Saúde, Campinas, SP v. 12, n 1 (15), p. 31-52 jan./jun. 2013 ISSN 1676-6806
} 
publicization where the call to volunteer or to solidarity of the society is empirically and ideologically actual.

KEYWORDS: State. Health. Social Security. Cancer.

\section{INTRODUÇÃO}

Uma questão que flutua no ar e diariamente nos desafia, no cenário polifônico e policromático brasileiro, é a Saúde que juntamente com a Previdência e Assistência Social, consignadas pela Constituição Federal de 1988 sob a rubrica da Seguridade Social, é um direito do (a) cidadão (ã) e um dever do Estado. Isto significa que a saúde, no Brasil, deve ser entendida e praticada como uma política de cunho universalista, democrática, distributiva e que não estigmatize seus (suas) usuários (as). Contudo, nos anos 1990, as três áreas da Seguridade Social foram institucionalizadas em ministérios e receitas diferentes, assinalando um desmonte do Estado associado "ao recuo da noção de proteção social universal” (TEIXEIRA, 2007, p. 10). Nessa tessitura do Estado brasileiro, a tendência neoliberal de diminuição da ação estatal investe na prática (reformas administrativas) e ideologicamente na ampliação e na manutenção da proteção social pública mínima, ampliando também os espaços não-governamentais com fins públicos, reforçando a perversa prática assistencialista da saúde (TEIXEIRA, 2007).

Ao se discutir a saúde como política, importa entender que o seu oposto, a doença, além de fato clínico, é um fenômeno sociopolítico, pois “a doença é uma realidade construída e o doente é um personagem social” (MINAYO, 1991). Aliás, “o conceito de doença nunca é inocente” (SONTAG, 1984, p. 104). Na múltipla relação saúde-doença, um dos principais problemas de saúde pública no Brasil e no mundo é o câncer (neoplasias malignas), que são patologias crônicas e degenerativas, que desde 2003, é a segunda causa de morte por doença na população nacional, e que, em 2030, será a primeira causa de mortalidade por doença no mundo, superando as doenças cardiovasculares (BRASIL, 2005; SILVA, 2010).

Em 2005, através da Portaria GM 2.439, o Ministério da Saúde, instituiu a Política Nacional de Atenção Oncológica (PNAO), sob responsabilidade do Instituto Nacional de Câncer (INCA), órgão governamental subordinado ao Ministério da Saúde, com sede na cidade do Rio de Janeiro. Através da PNAO, evidenciou-se uma retomada de aspectos apontados na Lei 8.080/90, quanto à organização dos serviços nos diferentes níveis de complexidade (atenção básica, média e alta complexidade). Isto é, a PNAO Serv. Soc. \& Saúde, Campinas, SP v. 12, n 1 (15), p. 31-52 jan./jun. 2013 ISSN 1676-6806 
acentua o câncer como questão de saúde pública. Contudo, apesar dos anos percorridos desde sua instituição, não se conseguiu refrear a incidência do câncer (BRASIL, 2005; SILVA, 2010).

Ianni diz que "todo aquele que migra sabe de onde parte mas não sabe onde chega; sabe o caminho que deixa mas não sabe qual encontra” (IANNI, 2004, p. 151). Diante dessa citação, inicio um percurso, que tem como ponto de partida muitas lacunas, cujo centro de discussão é o câncer como questão política e como política pública, especialmente, nos últimos vinte anos. Para tanto, neste artigo, far-se-á uma contextualização: 1) histórica da discussão do câncer, no Brasil, e sua relação com o Estado; 2) da construção do Instituto Nacional de Câncer, como agente diretivo da Política Nacional de Atenção Oncológica; 3) e da reforma administrativa do Estado brasileiro, na década de 1990, que teve como uma de suas diretrizes o processo de publicização, que se imiscui, entre avanços e retrocessos, paulatinamente em retrocessos com a saúde. Nesse percurso, veremos como mais uma vez diz Ianni, uma "pluralidade de Brasis [...] em taquigrafias de uma história difícil”.

\section{ACERCA DA HISTÓRIA SOCIOPOLÍTICA DO CÂNCER, NO BRASIL, E SEU PARALELO COM O MUNDO: A CONSTRUÇÃO DE UMA PROBLEMÁTICA}

De desequilíbrio de fluidos corporais, na escola hipocrática grega, passando pela descoberta de patologia local relacionada a diminutas estruturas orgânicas, no século XVIII, ao início do uso de intervenções cirúrgicas e da radioterapia (raios X e rádio), no século XIX, e da quimioterapia, no século XX, o câncer possui uma longa história social. A partir de meados do século XX, com o acelerado avanço da Medicina, intensificou-se o temor da sociedade quanto ao câncer, que passou a ser visto como o flagelo da modernidade. Ou seja, ao tempo em que se transformava em um objeto de estudo cada vez mais observado pela Medicina, socialmente, transformava-se em uma doença temerosamente associada à morte inevitável, perpassando por esse imaginário sociocultural a possibilidade de contágio e a interligação com características morais e psicológicas dos (as) doentes, como causas da enfermidade. O câncer transfigurava-se, assim, atrás de eufemismos, silêncios e metáforas (TEIXEIRA; FONSECA, 2007; CARVALHO, 2006; SONTAG, 1984). 
No período entre as duas guerras mundiais, ampliou-se a preocupação com a problemática, câncer, principalmente devido ao aumento epidemiológico da doença, que tendia a se relacionar com a elevação de melhores condições de vida da população, e concomitantemente, com o seu envelhecimento. Nesse contexto, o câncer tornou-se motivo de atenção dos Estados, das instituições de pesquisa e dos médicos em geral, por tomar o lugar de doenças avassaladoras do passado, que já estavam sob controle da Medicina. Além disso, teve-se a naturalização no cotidiano da sociedade de palavras de cunho militar, como guerra, luta e combate, no discurso ideológico acerca da doença (TEIXEIRA; FONSECA, 2007; CARVALHO, 2006; SONTAG, 1984).

Nas décadas de 1960 e 1970, iniciou-se a construção de um novo discurso ideológico no processo de prevenção e tratamento do câncer, agora entendido, como uma enfermidade crônica e degenerativa. Mediante essa construção social e discursiva, objetivava-se uma desconstrução da história da representação do câncer como mal medonho e incontrolável; um confronto entre a racionalidade médica, investida de um estatuto da verdade, e a irracionalidade simbólica, investida de uma concepção alegórica da doença (CARVALHO, 2006).

No âmbito da discussão acerca do câncer, podemos inserir o Brasil em uma relação permeada de contradições e vicissitudes, de avanços e retrocessos, e, principalmente, de tentativas ora frustradas ora exitosas. E como veremos mais a frente, diferentemente dos Estados Unidos e de países europeus, que tiveram a iniciativa privada como um dos principais motores, foi o Estado, no Brasil, que permitiu alavancar o ensino, a pesquisa e terapêutica do câncer.

\section{UMA RÁPIDA VOLTA AO PASSADO}

$\mathrm{O}$ interesse médico brasileiro, em fins do século XIX e início do século XX, quanto ao câncer relacionava-se à possibilidade de pertencimento ao campo médico internacional. Pois, não tinham como objetivo resolver um problema de saúde de extensão nacional, já que o câncer ainda tinha estatisticamente baixa incidência. No entanto, com a reforma sanitária de 1919, foi criado, no governo Epitácio Pessoa (1919-1922), o Departamento Nacional de Saúde Pública (DNSP). Ao incorporar em seu quadro de funcionários, um grande número de sanitaristas com formação específica em saúde pública, o DNSP fazia com que a ação em saúde se voltasse para novas doenças, cabendo à saúde pública o papel de agente principal na concepção e execução das atividades nesse campo e de coordenadora da ação da iniciativa filantrópica. Assim, "o Serv. Soc. \& Saúde, Campinas, SP v. 12, n 1 (15), p. 31-52 jan.jun. 2013 ISSN 1676-6806 
câncer como doença prevenível e mal possivelmente contagioso, passaria a ser foco dessa renovada saúde pública” (TEIXEIRA; FONSECA, 2007, p. 30).

No organograma da nova instituição, o câncer ficou a cargo da Inspetoria da Lepra e das Doenças Venéreas, e seu eixo de atuação se restringia ao Distrito Federal e se centrava no estabelecimento de estatísticas mais adequadas de óbito de câncer, além de informar a população sobre a prevenção da doença e esclarecer sobre formas alternativas de cura, que deveriam ser combatidas, como o charlatanismo (TEIXEIRA; FONSECA, 2007). Em 1923, a versão contagiosa do câncer determinou a criação de uma dotação orçamentária, oriunda de um fundo especial, através do Decreto $n^{0} 4.625$. Esse decreto não estipulou a fonte do financiamento, mas estabeleceu que o dinheiro deveria ser estornado ao Tesouro.

O câncer estaria assim iniciando sua trajetória na incorporação da agenda higienista como um incômodo visível e que deveria ser enfrentado através da iniciativa do campo médico-científico, o que resultaria em ações concretas do governo daí por diante (CARVALHO, 2006, p. 40).

Outro aspecto importante na legislação de 1920 dizia respeito à possibilidade de elaboração de acordos entre o Estado e associações ou estabelecimentos privados, no intuito de se fundar um instituto do câncer, responsável pelas pesquisas experimentais e tratamentos gratuitos aos (às) necessitados (as). O médico Eduardo Rabello³ propôs a parceria público/privado no controle do câncer, fosse através de investimentos na instalação de serviços de câncer em clínicas privadas ou através da criação de estruturas sanitárias, como departamentos e ministérios. Assim, anunciou a construção de um Hospital do Câncer pela Fundação Oswaldo Cruz como um programa de combate ao câncer do DNSP e co-financiado pelo empresário Guilherme Guinle ${ }^{4}$. Essa proposta não

\footnotetext{
${ }^{3}$ Eduardo Rabello foi médico e professor da Faculdade de Medicina do Rio de Janeiro, especialista em sífilis e doenças da pele, que desenvolveu, na década de 1920, trabalhos sobre a prevenção dos cânceres de pele e de útero. Foi o primeiro diretor do DNSP.

${ }^{4}$ Guilherme Guinle nasceu, em 1882, e faleceu, em 1960. Foi nacionalista e mecenas. Amigo de Carlos Chagas e Eduardo Rabello, Guilherme Guinle apoiou a realização de uma parte da política de saúde pública voltada para o combate a endemias urbanas como sífilis, câncer e lepra, que estavam a cargo da Inspetoria de Profilaxia da Lepra e Doenças Venéreas. Em 1922, ajudou a criar a Fundação Oswaldo Cruz, que trabalharia com o ensino, a pesquisa e o tratamento do câncer. Por isso, a proposta da criação do Hospital do Câncer. Apesar do peso político de seus patronos, a Fundação não obteve apoio financeiro substancial do governo federal. "De todo modo, a Fundação Oswaldo Cruz não se realizou [...]. Pode ter contribuído a falta de coesão dos médicos acerca da etiologia do câncer. [...] A trajetória da Fundação Oswaldo Cruz foi, antes de tudo, resultado de um erro de estratégia: tentava-se criar primeiro o Hospital, para depois formar o respectivo campo médico" (SANGLARD, 2005, p. 187; 190). Serv. Soc. \& Saúde, Campinas, SP v. 12, n 1 (15), p. 31-52 jan./jun. 2013 ISSN 1676-6806
} 
obteve êxito, pois, em 1935, dez anos após seu lançamento, Guilherme Guinle desligouse do projeto por falta de apoio do governo federal (TEIXEIRA; FONSECA, 2007; SANGLARD, 2005; CARVALHO, 2006).

A Inspetoria da Lepra e das Doenças Venéreas, apesar do esforço dos sanitaristas em trazer o câncer para a agenda da saúde pública, não obteve resultados imediatos. No relatório do ano de 1927, informava que a única medida com relação ao câncer posta em prática foi a ampliação de quesitos nos atestados de óbitos pela doença, na obtenção de dados mais confiáveis para as estatísticas, por isso, limitou-se a pôr em prática iniciativas pedagógicas sobre o câncer e as formas de evitá-lo ou tratá-lo precocemente. Os principais espaços institucionais de valorização do câncer pelo campo médico eram a Academia Nacional de Medicina, a Sociedade de Medicina e Cirurgia do Rio de Janeiro e os Congressos Médicos (TEIXEIRA; FONSECA, 2007; SANGLARD, 2005; CARVALHO, 2006).

Nos anos de 1930, a política governamental orientou-se na ordenação de demandas voltadas para o trabalho, educação e saúde, sendo que esta última teve, apesar de precariamente, um contexto favorável com a criação de um “estado sanitário” por meio do Ministério da Educação e Saúde Pública, em 1933, que ocorreu com Getúlio Vargas, no poder. Entre 1930-1945, houve uma vitória parcial da cidade sobre o campo, com a perda de fôlego das elites agrárias na direção sociopolítica do Estado brasileiro, o qual assumiu a tarefa de criar condições para o desenvolvimento do capitalismo no país, através de instituições e valores socioculturais pautados no ideário burguês. Daí, a implementação de reformas norteadas pelo desenvolvimento industrial e urbano brasileiro (IANNI, 1996).

Nesse ínterim, em 1931, o médico Mário Kroeff ${ }^{5}$ chefiou a construção de um pavilhão para o tratamento cirúrgico do câncer anexo ao Hospital da Triagem, depois chamado Hospital Estácio de Sá. O pavilhão foi concluído, em 1933, mas destinado à outra cadeira da Faculdade de Medicina, o que frustrou os objetivos de Kroeff. No governo de Getúlio Vargas, com a Constituição de 1934, que estabeleceu pela primeira

\footnotetext{
${ }^{5}$ Mário Kroeff, em uma viagem à Europa para estudar sífilis e doenças venéreas, em 1924, interessou-se pelo tratamento cirúrgico do câncer, com uso do aparelho de eletro cirurgia. Foi professor da Faculdade de Medicina da Universidade Federal do Rio de Janeiro. Em 1930, imbuiu-se do diagnóstico do câncer, do papel positivo da cirurgia e da ascendência da radioterapia. Trabalhou no sentido de convencer as autoridades políticas acerca da importância do câncer, no Brasil. Em 1937, o presidente Getúlio Vargas criou o Centro de Cancerologia e convidou Kroeff para dirigi-lo. Sua proposta era atendimento aos doentes, amparo social aos incuráveis e propaganda para o diagnóstico precoce da doença. Em 1944, criou o Hospital Asilo para os Cancerosos Incuráveis (atual Hospital Mário Kroeff). Faleceu em 1983.
}

Serv. Soc. \& Saúde, Campinas, SP v. 12, n 1 (15), p. 31-52 jan./jun. 2013 ISSN 1676-6806 
vez, no artigo 10, a União e os estados federados como os responsáveis pela saúde e assistência pública, e o Decreto $\mathrm{n}^{0} 24.814$ de julho deste ano, que assentou a base administrativa do plano de reorganização dos serviços de saúde pública, possibilitou-se pensar o tratamento do câncer a nível nacional (TEIXEIRA; FONSECA, 2007; CARVALHO, 2006).

Assim, o tratamento e cura do câncer foram apropriados pelo discurso científico de manutenção da vida, inserido na organização científica do trabalho, dado que a organização e tutela do trabalho industrial instituíram-se "no aparelhamento de uma massa urbana capaz de servir de mercado de consumo para bens não-duráveis, e principalmente alimentos, base para a constituição de um mercado autossustentável” (CARVALHO, 2006, p. 63). Em termos ideológicos, o Estado Nacional voltou-se para uma política de amparo ao homem brasileiro, pautada no progresso e no trabalho. Pois, "tratava-se de formalizar, em novos níveis, as condições de intercâmbio e funcionamento das forças produtivas no mercado brasileiro”, com foco na industrialização (IANNI, 1996, p. 34). Ressalta-se que apesar da apropriação discursiva e ideológica do câncer, no sentido de incentivar e aparelhar o Brasil rumo à industrialização, não houve nenhuma ação governamental efetiva no sentido de se construir um espaço oficial no tratamento do câncer, o que veio a ser iniciado apenas nos anos 1940, como será explanado adiante.

Em janeiro de 1937, foi instituída a Lei nº 378, também chamada de Reforma Capanema, de caráter centralizador e nacionalista da política de saúde, com a divisão do território em oito regiões, cada um contando com uma Delegacia Federal de Saúde. A Reforma Capanema expressava a explícita intervenção do Estado no incentivo do processo de desenvolvimento industrial. O Estado passou, então, a agir no sentido de resolver os problemas políticos, sociais e econômicos que se apresentavam na conjuntura nacional (TEIXEIRA; FONSECA, 2007; CARVALHO, 2006; IANNI, 1996).

No artigo 58 da Reforma Capanema, estabeleceu-se um Serviço de Saúde Pública no Distrito Federal, e dentro deste, o Centro de Cancerologia (CC) de cunho hospitalar-assistencial, que, em janeiro de 1939, foi transferido para os serviços de saúde da Prefeitura do Rio de Janeiro, significando a interrupção do projeto de cancerologia de âmbito nacional. Com esta interrupção ou retrocesso, em 1940, o grupo Serv. Soc. \& Saúde, Campinas, SP v. 12, n 1 (15), p. 31-52 jan.jun. 2013 ISSN 1676-6806 
de cancerologistas do CC iniciou um novo projeto: o da construção de um Instituto Nacional de Cancerologia. Em 1941, através do Decreto $\mathrm{n}^{0}$ 3.643, foi instituído separadamente o Serviço Nacional de Câncer (SNC), que incorporava definitivamente o câncer na pauta das ações de saúde pública, tendo como seu diretor o médico Mário Kroeff. O SNC tinha como objetivo a orientação e controle em todo o país da campanha contra o câncer. Mas, não teve como iniciar rapidamente o grande conjunto de suas atividades, limitando, em seu primeiro ano, a elaborar um inquérito epidemiológico sobre a doença nas principais capitais brasileiras e a dar continuidade às atividades já realizadas no CC. Isto é, “apesar da abrangência que agora sustentava o controle do câncer, o poder central não atribuiu recursos para uma real expansão das atividades no setor” (TEIXEIRA; FONSECA, 2007, p. 77).

Em 1942, as ações anticâncer vivenciaram a terceira intercepção com o repasse do Hospital Estácio de Sá à Polícia Militar. Paralelo ao estado precário do SNC, a partir de 1942, instituições privadas de todo o país começaram a ser incorporadas, mediante decreto, à campanha contra o câncer, significando o controle e orientação de espaços hospitalares organizados por uma instituição debilitada. Em 1945, com a deposição de Getúlio Vargas, a situação do SNC modificou-se. Pois o governo do presidente interino, José Linhares ${ }^{6}$, propiciou, em 1946, através do Decreto-Lei $n^{\circ}$ 8.824, condições para aquisição definitiva do terreno da Praça Cruz Vermelha (Rio de Janeiro), onde seria instalada a sede do Instituto Nacional de Câncer (TEIXEIRA; FONSECA, 2007; CARVALHO, 2006).

Nesse período pós-1945, o SNC teve suas duas vertentes, representadas pela Seção de Controle e pelo Instituto Nacional de Câncer, institucionalizadas. A Seção de Controle ampliou sua capacidade propositiva no campo das políticas de saúde e o Instituto Nacional de Câncer começou um processo de ampliação e modernização de suas atividades que o transformou no mais importante centro latino-americano de tratamento e pesquisa sobre o câncer. Esse processo relacionou-se principalmente ao papel dos cancerologistas em garantir o monopólio em relação às políticas públicas para combate à doença (TEIXEIRA; FONSECA, 2007; SANGLARD, 2005; CARVALHO, 2006).

\footnotetext{
${ }^{6}$ A presidência do Brasil ficou a cargo de José Linhares no período de 29/10/1945 a 31/01/1946. Serv. Soc. \& Saúde, Campinas, SP v. 12, n 1 (15), p. 31-52 jan./jun. 2013 ISSN 1676-6806
} 


\section{INSTITUTO NACIONAL DE CÂNCER E SUA ÍNTIMA RELAÇÃO COM O ESTADO: OS PERCALÇOS DE UMA POLÍTICA - PARTE I}

Na década de 1950, o Instituto Nacional de Câncer, com novos aportes de recursos, conseguiu ampliar seu pessoal e reestruturar suas atividades em várias áreas relacionadas às especialidades médicas e cirúrgicas; celebrar convênios com instituições locais e intensificar suas ações de pesquisa e tratamento. Os ideais desenvolvimentistas intensificados reforçaram o interesse do Estado no controle do câncer, favorecendo a consolidação do SNC e do Instituto de Câncer. No segundo governo Vargas (1951-1954), a ação da saúde pública foi limitada à continuidade das atividades e arranjos institucionais forjados no Estado Novo (TEIXEIRA; FONSECA, 2007). Nesse período, a diretriz geral do governo era o abandono da doutrina liberal, para fortalecer a economia nacional, através do estreitamento das relações Estado e economia, no processo de intervenção no domínio econômico. Devido à falta de interesse da iniciativa privada, o Estado foi compelido a assumir novos encargos para acelerar o desenvolvimento econômico e se aparelhar adequadamente (IANNI, 1996).

O período que se estende até o golpe de 1964 apresenta acontecimentos importantes no campo da saúde pública e, consequentemente, no da política de controle do câncer. Um deles é a criação do Ministério da Saúde, em 1953, que, embora, não tenha significado um grande avanço para a saúde por ter sido destinado a apenas um terço dos recursos alocados no antigo Ministério da Educação e Saúde Pública, tinha como pano de fundo uma nova forma de pensar a saúde, chamada de sanitarismo desenvolvimentista. A ideia central dessa concepção era da proporcionalidade direta do nível de saúde da população ao seu grau de desenvolvimento econômico. Em relação ao câncer, apontava-se o caminho de seu controle no país por uma forte ação estatal na orientação e supervisão das ações da iniciativa privada, na suplementação de recursos às instituições de tratamento e na manutenção de centros de referência nos diversos aspectos do controle da doença (TEIXEIRA; FONSECA, 2007; CARVALHO, 2006).

No governo de Juscelino Kubitschek (1955-1960), houve uma profunda transformação do sistema econômico, com o Programa de Metas, que acelerou o desenvolvimento econômico; impulsionou o setor privado nacional e estrangeiro; Serv. Soc. \& Saúde, Campinas, SP v. 12, n 1 (15), p. 31-52 jan./jun. 2013 ISSN 1676-6806 
implicou em uma mudança qualitativa na figura do Estado, o que Ianni (1996) chama de hipertrofia do Executivo, reelaborando a dependência estrutural. Assim, a industrialização deixou de ser um processo induzido pelo setor externo, tornando-se uma política econômica de associação e interdependência.

No campo da saúde, investiu-se no controle das chamadas doenças de massas, que propunha pôr o Estado a serviço da superação dos entraves para o desenvolvimento do Brasil por meio de uma ação planejadora que superasse questões relativas à pobreza e à saúde. Nesse governo, foram destinados maiores recursos ao SNC, possibilitando a ampliação das verbas destinadas às instituições privadas filantrópicas ou dos estados que se vinculavam ao Serviço, e inaugurou-se a sede própria do Instituto Nacional de Câncer, em 1957 (TEIXEIRA; FONSECA, 2007; IANNI, 1996).

Nos anos de 1960, principalmente, após-1964 nos governos militares, contextualizados pela instabilidade política e social e pela progressiva perda de direitos civis, a saúde pública brasileira, o SNC e o Instituto de Câncer passaram por transformações significativas. A política anticâncer configurada na década anterior sofreu um abrupto retrocesso, quando o INCA atravessou uma forte crise determinada pelo encaminhamento mais geral da política de saúde voltada para a privatização dos serviços,

[...] em que a contratação de hospitais privados e credenciamento de prestadores de serviços passaram a ser práticas dominantes do INPS, como por exemplo, a adoção dos critérios do mercado ou da eficiência empresarial na gestão dos organismos públicos (TEIXEIRA, 2007, p. 13).

O Estado atuou, portanto, segundo uma lógica de prestação de serviços públicos, que favorecia interesses privados e fortalecia o mercado privado de saúde, em um processo de mercantilização da medicina (TEIXEIRA; FONSECA, 2007; DRAIBE, 1990). O que ocorreu no Brasil, foi uma fase nova no processo de reprodução e concentração do capital, em nível internacional. E, paralelamente, desenvolvia-se uma fase nova nas relações entre o Estado e a empresa privada. Isto é, sob os governos militares convergiram na economia brasileira: as tendências expansionistas das empresas multinacionais e a política anti-inflacionária (IANNI, 1996).

Em 1967, foi aprovado o Decreto-Lei $n^{0}$ 200, que teve o Plano Nacional de Saúde (PNS) o tradutor de suas diretrizes no estímulo à ação no campo da saúde como um campo de investimento econômico, estreitando ainda mais a relação entre o governo federal e os produtores privados de serviços de saúde. Priorizava-se a área da medicina Serv. Soc. \& Saúde, Campinas, SP v. 12, n 1 (15), p. 31-52 jan./jun. 2013 ISSN 1676-6806 
assistencial em detrimento da saúde pública, canalizando exclusivamente para o Ministério da Saúde as ações de assistência médico-hospitalar, até então sob responsabilidade da Previdência Social. Ainda em 1967, no mês de dezembro, com a promulgação do Decreto $n^{\circ}$ 61.968, que instituiu no Ministério da Saúde a Campanha Nacional de Combate ao Câncer (CNCC), inaugurada oficialmente em 1968, o Instituto Nacional de Câncer deixou de ser o principal formulador das políticas de combate à doença no país (TEIXEIRA; FONSECA, 2007).

Em 1968, o INCA foi transferido para o Ministério da Educação, ficando subordinado à Federação de Escolas Federais Isoladas do Estado da Guanabara (atual Uni-Rio), e o câncer relacionado a doenças que não tinham um caráter de saúde pública. O Instituto teve suas atividades no campo do ensino restringidas, o que fez com que, em fins dos anos 1960, passasse por um processo de interrupção (mais um retrocesso) de sua expansão institucional. Três anos após essa interrupção, em 1971, o INCA voltou a ser gerenciado novamente pelo Ministério da Saúde com inúmeros problemas dentre eles: reduzida capacidade de atendimento; diminuição no número de médicos e de funcionários e escassez financeira (TEIXEIRA; FONSECA, 2007).

Na segunda metade da década de 1970, ressurgiu no cenário nacional os debates relativos à descentralização, à atenção primária de saúde e à participação comunitária, preconizadas pela Organização Mundial de Saúde (OMS). Esse panorama geral de alterações e discussões institucionais repercutiu diretamente sobre o campo de ação de controle do câncer: o SNC foi transformado em Divisão Nacional do Câncer (DNC), que, em 1978, foi substituída pela Divisão Nacional de Doenças Crônico-Degenerativas (DNDCD); implantou-se o Plano Nacional de Combate ao Câncer (PNCC), caracterizado especialmente pelo combate ao câncer em âmbito nacional e pela formação de profissionais especializados(as); e criou-se, em 1975, o Programa de Controle do Câncer (PCC), efetivado entre 1976-1980, sendo que em sua justificativa trazia uma situação alarmante do câncer no Brasil. As medidas e reformas sofridas no campo da oncologia brasileira evidenciavam "que o câncer estava ganhando relevância política na agenda de prioridades da saúde, fortalecendo-se como problema público” (TEIXEIRA; FONSECA, 2007, p. 125).

Nos primeiros anos da década de 1980, a gestão do INCA ficou a cargo tanto do Ministério da Saúde como do Ministério da Previdência e Assistência Social, Serv. Soc. \& Saúde, Campinas, SP v. 12, n 1 (15), p. 31-52 jan./jun. 2013 ISSN 1676-6806 
possibilitando melhorias significativas em suas atividades, e o seu retorno como protagonista no campo das ações médicas e das formulações de políticas para o controle do câncer no país. O sistema de cogestão (Portaria Interministerial $n^{0}$ 09, de 26 de agosto de 1980) do INCA foi uma inversão na lógica anterior de mercantilização da saúde e uma abertura de parceria entre instituições públicas. No decorrer da década de 1980, foram realizadas a VII e a VIII CNS, que repercutiram diretamente sobre o INCA (TEIXEIRA; FONSECA, 2007).

A VIII CNS consolidou as propostas de criação de um sistema único e descentralizado de saúde, que assegurasse o acesso universal à população brasileira. As propostas aprovadas na VIII CNS consubstanciaram a Reforma Sanitária, cujos princípios fundamentais foram incorporados na Constituição Federal de 1988 (BRAVO; MATOS, 2001). Cabe sublinhar, porém, que as ações de saúde pública e o atendimento hospitalar de urgência, na década de 1980, foram realizados em uma minguada face universal em um modelo de tipo hospitalocêntrico, que privilegiou a assistência médica ambulatorial e hospitalar, apoiado em recursos da Previdência Social e assentado na compra de serviços do setor privado, fazendo com que a saúde pública preventiva não obtivesse melhorias nos indicadores sociais, como os de mortalidade, morbidade e esperança de vida (DRAIBE, 1990).

A Reforma Sanitária da década de 1980 incorporou um projeto societário fundado em uma

[...] democracia de massas, com ampla participação social conjugando as instituições parlamentares e os sistemas partidários com uma rede de organização de base, salientando-se os sindicatos, comissões de fábrica, organizações profissionais e de bairros, movimentos sociais urbanos e rurais (BRAVO; MATOS, 2001, p. 198-99).

Em outras palavras, a Reforma Sanitária, fruto de lutas e mobilizações sociais, principalmente dos profissionais da saúde, propôs uma relação diferenciada do Estado com a sociedade, ao incentivar a presença e participação de novos sujeitos sociais na definição das políticas sociais através de Conselhos e Conferências de Saúde, que são mecanismos inovadores na gestão política da saúde. Pois, mesmo não governando as políticas, esses mecanismos estabelecem parâmetros utilizados pela sociedade nas exigências de construção democrática das informações e consequentemente da transparência do uso dos recursos e demais ações governamentais. Afinal, a preocupação central da Reforma é assegurar a atuação do Estado em função da 
sociedade, pautada na concepção de Estado democrático e de direito, responsabilizandoo pela elaboração de políticas sociais e de saúde (BRAVO; MATOS, 2001).

\section{INSTITUTO NACIONAL DE CÂNCER E SUA ÍNTIMA RELAÇÃO COM O ESTADO: OS PERCALÇOS DE UMA POLÍTICA - PARTE II}

Na década de 1990, o campo da saúde, no Brasil, passou por momentos distintos em relação à Reforma Sanitária. As conquistas jurídico-institucionais, como a Constituição Federal de 1988 e a Lei Orgânica da Saúde/Leis 8.080/90 e 8.142/90, foram acompanhadas de questionamentos conservadores quanto ao SUS e à saúde como direito social e de normatizações da contrarreforma na saúde (BRAVO; MATOS, 2001). De acordo com Vianna, a saúde no Brasil foi “americanizada”,

[...] na direção de um Welfare State liberal e residual, [ou seja], houve um "desmonte" da proteção pública de dimensões universalista e garantidora de direitos sociais; [...] em que o Estado divide com o mercado a provisão de bens e serviços, restringindo a proteção pública aos mais pobres, ou provendo um mínimo de benefícios a ser complementado no mercado pelos que têm condições de acesso. Trata-se, sem dúvida de um Estado intervencionista, mas direcionando o fundo público para o capital [...] (TEIXEIRA, 2007, p. 9).

Antes de adentrarmos na análise dos últimos vinte anos de construção da política de combate e controle do câncer, no Brasil, é necessário entendermos a configuração da tessitura política brasileira e sua íntima e subalterna relação com a tessitura política mundial de cunho neoliberal. Para tanto, faz-se mister tocarmos na construção e crise do Estado de Bem-Estar Social, no seu oposto, o Estado de Mal-Estar Social (SOARES, 2002).

O Welfare State é um fenômeno do século XX, que se expandiu e se institucionalizou no período do pós-guerra, caracterizado pela "provisão de serviços sociais", pela cobertura das "mais variadas formas de risco da vida individual e coletiva”, o que o tornou "um direito assegurado pelo Estado a camadas bastante expressivas da população dos países capitalistas” (ARRETCHE, 1995, p. 3). Ou seja, o Welfare State foi a adoção de políticas anticíclicas keynesianas, que apresentava o reaquecimento da economia capitalista através da intervenção direta do Estado mediante políticas sociais e do pleno emprego, em um processo de reencontro da economia com a 
democracia (reequilíbrio entre as forças econômicas e políticas), permitindo o surgimento de uma nova esfera pública não-burguesa e a publicização de classes sociais.

Quanto à definição do Welfare State, baseio-me em Sônia Draibe, que o entende

[...] no âmbito do Estado capitalista, [como] uma forma de regulação social que se expressa pela transformação das relações entre o Estado e a economia, entre o Estado e a sociedade, a um dado momento do desenvolvimento econômico. [...]. Concretamente, trata-se de processos que, uma vez transformada a própria estrutura do Estado, expressam-se na organização e produção de bens e serviços coletivos, na montagem de esquemas e transferências sociais, na interferência pública sobre a estrutura de oportunidades de acesso a bens e serviços públicos e privados e, finalmente, na regulação da produção e de bens e serviços sociais privados (DRAIBE, 1990, p. 2-3).

Este conceito de Welfare State incorpora a perspectiva da responsabilidade estatal na regulação do mercado, isto é, a intervenção do Estado na regulação das relações sociais e econômicas. Para Draibe, a construção do welfare state brasileiro não foi linear. Assim, tem-se o primeiro período de construção do welfare state, entre 19301943, com a criação dos institutos de aposentadorias e pensões, a legislação trabalhista e as alterações nas áreas de política de saúde e educação; o segundo período que corresponde ao regime democrático dos anos de 1945-1964, em que se seguem movimentos de inovação legal-institucional (a saúde inclusa) e a expansão do sistema de proteção social nos moldes e parâmetros do período anterior; e o terceiro período de consolidação nos anos de 1960-1970, com a transformação do aparato institucional e financeiro das políticas sociais pelo conjunto das medidas legislativas estabelecidas. Contudo,

[...] as políticas sociais, na sua maioria, reproduzem o sistema de desigualdades preexistentes na sociedade. São escassos seus aspectos redistributivos e igualitários, teoricamente presentes tão-somente no âmbito da educação básica (obrigatória e gratuita) e no de saúde (atendimento de urgência) (DRAIBE, 1990, p. 10).

Essa regulação ou intervenção estatal do Welfare State tinha dois objetivos principais: "manter o equilíbrio entre oferta e demanda e assegurar benefícios de proteção aos (às) trabalhadores (as) em momento de perda da capacidade laborativa e, mais globalmente, aos (às) cidadãos (ãs) em situações de dificuldades econômicas e sociais” (BEHRING, BOSCHETTI, 2006, p. 98). No Brasil, mesmo não tendo existido um welfare state no sentido clássico do termo, houve uma forma particular de Estado de Bem-Estar Social, ou seja, “no Brasil, país onde se costuma dizer que nunca existiu um 
Estado de Bem-Estar, por comparação a um suposto esquema coerente, consistente e generoso de bem-estar primeiro-mundista”, com políticas sociais redistributivistas e promotoras do pleno emprego, devido às particularidades contextuais do Brasil, que se inseriu tardiamente e prevalecendo a elite econômica no cenário do mercado internacional, por meio de uma revolução de cima para baixo, em uma proposta de desenvolvimentismo (PEREIRA, 2001, p. 28). Concordo com Draibe (1990) que caracteriza o Estado de bem-estar social brasileiro como meritocráticoparticularista-clientelista.

O sistema de proteção social brasileiro suplementou-se por meio de mecanismos de corte assistencialista e em suas relações com os grupos de interesse e com o sistema político, adquiriu, desde a fase de introdução, uma conotação clientelista, meritocrática e particularista. O Brasil, em meados da década de 1980, gastava na área social 18,3\% do Produto Interno Bruto (PIB), quase como um país desenvolvido, apresentando, no entanto, resultados insuficientes quanto à melhoria na redistribuição de renda e na universalização dos serviços sociais. Isso é devido à intervenção estatal brasileira ter se fundado na capacidade contributiva do(a) trabalhador(a), o que a autora chama de distribuição primária de renda. O welfare state brasileiro seguiu o caminho conservador, por isso, negou substancialmente o bem-estar através do progresso econômico. A ausência do conceito de welfare state, no Brasil, representa a imagem negativa das políticas sociais brasileiras quanto aos seus reduzidos efeitos e seus baixos graus de eficácia e efetividade sociais, como também simbolicamente, a ausência de integração e mobilização das políticas sociais (DRAIBE, 1990).

Mas, foi apenas na década de 1990, no Brasil, com a crise dos welfare states, que houve a entrada retardatária dos ajustes estruturais neoliberais, que tem como uma de suas principais estratégias a privatização dos serviços sociais (SOARES, 2002). Dessa forma, o Brasil ficou sob a áurea do milagre salvacionista do pensamento único da reforma neoliberal do Estado, que visava simultaneamente combater a ineficiência/ineficácia/incapacidade do Estado e valorizar as potencialidades do mercado, único capaz de promover duplamente crescimento econômico e desenvolvimento social. De acordo com Soares, Em síntese, esse novo modelo de acumulação implica que: os direitos sociais perdem identidade e a concepção de cidadania se restringe; Serv. Soc. \& Saúde, Campinas, SP v. 12, n 1 (15), p. 31-52 jan./jun. 2013 ISSN 1676-6806 
aprofunda-se a separação público-privado e a reprodução é inteiramente devolvida para este último âmbito; a legislação trabalhista evolui para uma maior mercantilização (e, portanto, desproteção) da força de trabalho; a legitimação (do Estado) se reduz à ampliação do assistencialismo (SOARES, 2002, p. 13).

No Brasil, com os dois governos FHC (1995-2002), a contrarreforma estatal foi triunfante: privatizações, priorização do mercado em detrimento de políticas sociais universais, publicização, a prática do gerencialismo na administração para combater o burocratismo emperrador do desenvolvimento econômico e social, entre outros aspectos (BEHRING, 2003). Tem-se, assim, a indicação de "uma sociedade que, em vez de emancipada, mostra-se sobrecarregada com tarefas e responsabilidades que, por dever de cidadania, pertencem ao Estado” (PEREIRA, 2001, p. 32). Tudo isso monitorizado pelo Fundo Monetário Internacional (FMI), Banco Mundial e Organização Mundial de Comércio (OMC), que Ianni (2003) chama de “santíssima trindade do capital em geral”. A orquestra do processo fica sob responsabilidade da mídia impressa e eletrônica mundial, também composta por corporações transnacionais.

O INCA, durante este contexto, relacionou-se e relaciona-se com a incorporação das ações de assistência médica pelo Ministério da Saúde; a redefinição das relações e das atribuições das ações de saúde entre governos federal, estaduais e municipais; e a reconfiguração da relação entre serviços privados de saúde e saúde pública.

A “americanização" da saúde brasileira apresenta dois Brasis: o Brasil do sistema público de saúde, destinado aos (às) pobres, e o Brasil do sistema privado de saúde, destinado aos (às) consumidores (as). "É do interesse dessas empresas que a saúde pública ande mal das pernas e que a previdência sofra um intenso enxugamento, pois aliciam mais clientes justamente quando os serviços não funcionam a contento" (VIANNA, 2001, p. 192). Assim, as reformas para o campo da saúde tiveram como propostas: a focalização, a privatização (estímulo ao seguro privado), a descentralização dos serviços em nível local e as parcerias com a sociedade, com incentivo da refilantropização, “ou seja, a desprofissionalização com a utilização de agentes comunitários e cuidadores para realizarem atividades profissionais” (BRAVO; MATOS, 2001, p. 201).

Com a extinção do Instituto Nacional de Assistência Médica da Previdência Social (INAMPS), em 1990, foram incorporadas ao Ministério da Saúde, as ações de assistência médica, antes executadas pelo Ministério da Previdência. Esse movimento recolocou o Ministério da Saúde no papel de pedinte, ajudando, a implodir o conceito de Serv. Soc. \& Saúde, Campinas, SP v. 12, n 1 (15), p. 31-52 jan./jun. 2013 ISSN 1676-6806 
seguridade social (BRAVO, MATOS, 2001). Em 1993, foi promulgada a Norma Operacional (NOB/93), que criou as modalidades de municipalização da saúde, estabelecendo os "parâmetros para que os estados e municípios definissem as atividades de saúde que incorporariam como suas atribuições” (TEIXEIRA; FONSECA, 2007, p. 142). Em 1996, teve-se a promulgação da Norma Operacional (NOB/96), que incentivou a intensificação das ações dos estados e municípios na área de saúde pública e o comprometimento com investimentos na área de medicina preventiva. A NOB/96 é a "expressão dos efeitos cumulativos do longo processo de implantação da descentralização na saúde no Brasil, mas também - e principalmente - dos incentivos à adesão envolvidos em suas regras” (ARRETCHE, 2003, p. 341).

Com a Lei Orgânica da Saúde/Lei nº 8.080/90, no artigo 41, o INCA foi identificado como órgão de referência no estabelecimento de parâmetros e avaliação da prestação de serviços oncológicos ao SUS. Coube, então, ao INCA assessorar, executar e coordenar a Política Nacional de Prevenção e Controle do Câncer. Além da Lei $\mathrm{n}^{0}$ 8.080/90, os decretos presidenciais de 1991, 1998 e 2000 reforçaram o papel do INCA como órgão responsável por assistir o Ministério da Saúde na formulação da Política Nacional e como agente condutor das ações do Ministério na prestação de serviços oncológicos a nível nacional.

Ainda na década de 1990, foram implementadas ações como a ampliação dos registros de câncer e a expansão da assistência oncológica, através dos Centros de Alta Complexidade, sendo que, em 1998, surgiu o Programa Nacional de Controle do Câncer do Colo do Útero (Viva Mulher); e, em 2000, as primeiras iniciativas para o controle do câncer de mama. Essas ações culminaram, em 2005, com a Política Nacional de Atenção Oncológica (PNAO) - Portaria 2.439 -, que estabeleceu as diretrizes para o controle do câncer no Brasil desde a promoção da saúde até os cuidados paliativos. A PNAO “propõe e orienta a organização da Rede de Atenção Oncológica nos Estados, uma estratégia de articulação institucional voltada para superar a fragmentação das ações e garantir maior efetividade e eficiência no controle do câncer” (PARADA, et al, 2008, p. 201).

Os componentes da PNAO são: vigilância em saúde, enfatizando o controle do tabagismo, promoção da alimentação saudável e da atividade física, preservação do meio ambiente e segurança ocupacional, articulada à política nacional de promoção da Serv. Soc. \& Saúde, Campinas, SP v. 12, n 1 (15), p. 31-52 jan./jun. 2013 ISSN 1676-6806 
saúde; ampliação da cobertura com assistência qualificada pautada nos princípios de universalidade, integralidade e humanização; definição de parâmetros técnicos para avaliação, controle e regulação dos serviços; educação permanente dos(as) profissionais; fortalecimento dos sistemas de informação; avaliação tecnológica e incentivo à pesquisa (PARADA, et al, 2008).

No entanto, como ressalta Silva (2010), as iniciativas do governo federal em construir mecanismos legais, como a PNAO, vinculados à proposta inicial do SUS não estão sendo acompanhadas de condições concretas para a sua efetivação. Pois quanto ao câncer, as bases legais através da iniciativa política pública estatal para seu controle e combate foram postas, mas essa política não recebe o devido financiamento para sua realização, pois,

No Brasil, em oncologia a luta é ainda pela garantia das mínimas condições para o diagnóstico precoce de cânceres com potencial de tratamento e cura em estadiamentos iniciais e pela universalização efetiva - universalidade acompanhada de equidade e integralidade desses tratamentos e incorporação de tecnologias acessíveis ao conjunto da população (SILVA, 2010, p. 180).

Em relação ao financiamento de políticas públicas sociais (como a PNAO), Arretche, ao falar da limitada capacidade de investimento do Ministério da Saúde, destaca que o "gasto público em alta e média complexidade é fortemente dependente da oferta de hospitais privados e filantrópicos, os quais tendem a concentrar-se em municípios com renda mais elevada” (ARRETCHE, 2003, p. 341-342). No caso do INCA, tem-se uma significativa parcela de seiscentos (as) cuidadores (as) voluntários (as), no INCAVOLUNTÁRIO, o que perpassa substancialmente a discussão da refilantropização ou publicização das ações sociais do Estado, no repasse dos serviços sociais e científicos estatais para a sociedade civil. O INCAVOLUNTÁRIO desenvolve atividades para os (as) usuários (as) do Instituto, principalmente, nas unidades hospitalares. Entre as ações desse setor estão o apoio aos (às) pacientes, humanização do ambiente hospitalar (um dos componentes da PNAO, como visto acima) e captação de recursos.

Na análise acerca da reforma do Estado atual, Bravo e Matos (2001) distinguem os serviços sociais e científicos, que apesar de não precisarem ser privatizados, não cabem ser executados pelo Estado, ficando a cargo das Organizações Públicas NãoEstatais (OPNES). Os serviços de saúde estão inseridos neste setor, podendo ser transformados em OPNES, sociedades de direito privado, sem fins lucrativos, 
administradas com subvenções dos cofres públicos. O INCAVOLUNTÁRIO ao atuar com cuidadores (as) em substituição de profissionais especializados (as) conjuga, dentro do Instituto Nacional de Câncer, agente diretivo da PNAO, “a desresponsabilização do Estado na garantia de direitos sociais, e a participação das ONG's e do mercado na execução das políticas sociais, que não podem garantir direitos conquistados, pois, atuam de forma pontual e localizada” (TEIXEIRA, 2007, p. 16).

A classe trabalhadora em tempos de neoliberalismo tem sofrido os efeitos do retrocesso dos direitos sociais através dos limitados financiamentos públicos e da intensificação das desigualdades sociais. Ocorre, dentre as consequências desse processo, o retorno à família e à sociedade civil sem fins lucrativos como agentes do bem-estar social, esvaziando o setor público e desmantelando os serviços sociais públicos. "Isto vem implicando a renúncia explícita do Estado em assumir sua responsabilidade na prestação de serviços sociais (sobretudo saúde e educação) em bases universais” (SOARES, 2002, p. 79-80). Quanto às pessoas portadoras de câncer, esses efeitos são agudizados pela dificuldade de acesso ao diagnóstico precoce e ao tratamento preconizado e pela limitada proteção social desempenhada pelo Estado.

\section{CONSIDERAÇÕES FINAIS}

O Brasil, no período em que a maioria dos países da América Latina implantava os ajustes estruturais neoliberais, esteve na contramão com a Constituição Federal de 1988, e no campo da saúde, com a Lei Orgânica da Saúde/Leis 8.080/90 e 8.142/90. Mas, apesar desses avanços na garantia dos direitos sociais, a década de 1990 configurou o gradativo desmonte da Seguridade Social, em que a área da saúde teve esfacelada a Reforma Sanitária da década de 1980, em um processo de contrarreforma, que implantou o projeto societário de uma democracia restrita, em que o projeto saúde ficou articulado ao mercado, e concomitantemente, à publicização dos serviços sociais e científicos.

A política nacional de combate e controle ao câncer, inserida neste cenário, e atualmente conhecida como Política Nacional de Atenção Oncológica, instituída em 2005, e dirigida pelo Instituto Nacional de Câncer, órgão pertencente ao Ministério da Saúde, teve um percurso histórico permeado de avanços e retrocessos, que consolidou o 
câncer como uma problemática política e de política pública. De doença de baixa incidência estatística, na década de 1920, à segunda causa de morte por doença, no Brasil, na primeira década do século XXI, o câncer foi e é uma questão contínua e reiteradamente discutida e rebatida, nesses últimos noventa anos, tornando-se gradualmente uma questão de saúde pública. Como dito, ao contrário dos países europeus e dos Estados Unidos, a problemática do câncer, no Brasil, teve no Estado o seu propulsor. Todavia, não foi uma relação harmoniosa e linear. E, sim, uma relação cheia de percalços, pois não poderia deixar de ser uma relação à brasileira.

\section{REFERÊNCIAS}

ARRETCHE, M. Emergência e desenvolvimento do welfare state: teorias explicativas. BIB, n. 39, Rio de Janeiro: 1995, p. 3-40.

ARRETCHE, M. Financiamento federal e gestão local de políticas sociais: o difícil equilíbrio entre regulação, responsabilidade e autonomia. Ciência \& Saúde Coletiva, 08 (02): 331-45, 2003.

BRASIL. Ministério da Saúde. Portaria n. 2.439 de 08 de dezembro de 2005. Institui a Política Nacional de Atenção Oncológica.

BRAVO, M. I. S. MATOS, M. de C. A saúde no Brasil: reforma sanitária e ofensiva neoliberal. In: BRAVO, M. I., PEREIRA, P. A. P. (Orgs.). Política Social e Democracia. São Paulo: Cortez; Rio de Janeiro: UERJ, 2001.

BEHRING, E. R. Contra-reforma do Estado, seguridade social e o lugar da filantropia. Serviço Social \& Sociedade. N. 73, Cortez, mar./2003, p. 101-19. (Políticas públicas e Sociedade Civil).

BEHRING, E. R.; BOSCHETTI, I. Política Social: fundamentos e história. São Paulo: Cortez, 2006.

CARVALHO, A. O. R. de. O Instituto Nacional de Câncer e sua memória: uma contribuição ao estudo da invenção da cancerologia no Brasil. Dissertação. Fundação Getúlio Vargas. Rio de Janeiro, 2006.

DRAIBE, S. M. As políticas sociais brasileiras: diagnósticos e perspectivas. In: DRAIBE, S. M. Para a década de 1990. Prioridades e perspectivas de políticas públicas. IPEA/IPLAN: Brasília, 1990.

IANNI, O. Estado e planejamento econômico no Brasil. 6 eds. Rio de Janeiro: Civilização Brasileira, 1996. 
IANNI, O. Tendências do pensamento brasileiro. Tempo Social. Revista de Sociologia. USP, São Paulo, v. 12, n. 02, p. 55-74, novembro de 2000.

IANNI, O. Sociologia do futuro. In: BARREIRA, C. (Org.). A Sociologia no tempo. Memória, imaginação e utopia. São Paulo: Cortez, 2003.

IANNI, O. Uma longa viagem. Tempo Social. Revista de Sociologia. USP, São Paulo, p. 153-166, junho de 2004.

MINAYO, M. C. de S. Abordagem antropológica para avaliação de políticas sociais. Revista de Saúde Pública, São Paulo, v. 25, n. 03, p. 233-38, 1991.

PARADA, R. et al. A Política Nacional de Atenção Oncológica e o papel da atenção básica na prevenção e controle do câncer. Rev. APS, v. 11, n. 02, p. 199-206, abr./jun., 2008.

PEREIRA, L. C. B. A reforma do Estado dos anos 90: lógica e mecanismos de controle. Cadernos MARE da Reforma do Estado. Brasília: Ministério da Administração Federal e Reforma do Estado, 1997.

PEREIRA, P. A. P. Mudanças estruturais, política social e papel da família: crítica ao pluralismo de bem-estar. In: SALES, M. A. MATOS, M. C. de. LEAL, M. C. (Orgs.). Política social, família e juventude. Uma questão de direitos. 2. ed. São Paulo: Cortez, 2001.

SANGLARD, G. P. Entre os salões e o laboratório: filantropia, mecenato e práticas científicas - Rio de Janeiro, 1920-1940. Tese de doutorado, Rio de Janeiro: FIOCRUZ, 2005.

SILVA, L. B. Condições de vida e adoecimento por câncer. Libertas, Juiz de Fora, v. 10, n. 02, p. 172-87, jul./dez., 2010.

SONTAG, S. A doença como metáfora. Tradução de Márcio Ramalho. Rio de Janeiro: Edições Graal, 1984.

SOARES, L. T. Os custos sociais do ajuste neoliberal na América Latina. 2. ed. São Paulo: Cortez, Coleção Questões da Nossa Época; v. 78, 2002.

TEIXEIRA, L. A. FONSECA, C. O. De doença desconhecida a problema de saúde pública: O INCA e o controle do câncer no Brasil. Rio de Janeiro: Ministério da Saúde, 2007.

TEIXEIRA, S. M. Reforma da Previdência Social no Brasil: modernização ou desmonte da seguridade social? Serviço Social e Contemporaneidade: Revista do Departamento Serv. Soc. \& Saúde, Campinas, SP v. 12, n 1 (15), p. x31-52 jan.jun. 2013 ISSN 1676-6806 
de Serviço Social/Universidade Federal do Piauí. Ano V, n. 05, Teresina, EDUFPI, 2007.

VIANNA, M. L. T. W. O silencioso desmonte da seguridade social no Brasil. In: BRAVO, M. I.; PEREIRA, P. A. P. (Orgs.). Política Social e Democracia. São Paulo: Cortez; Rio de Janeiro: UERJ, 2001. 